Сайков А.Д., Скугаревский О.А., Минзер М.Ф.

\title{
Агрессивное поведение лиц с алкогольной зависимостью В контексте критериев патологии при оценке биоэлектрической активности головного мозга
}

Белорусский государственный медицинский университет, г. Минск, Республика Беларусь

antonsaikov@mail.ru,skugarevsky@gmail.com,neirof@mail.ru

Сайков А.Д., Скугаревський О.О., Мінзер М.Ф. Агресивна поведінка осіб з алкогольною залежністю в контексті критеріїв патології при оцінці біоелектричної активності головного мозку Білоруський державний медичний університет
Saikov A., Skugarevsky O., Minzer M. Aggressive behavior of persons with alcohol dependence in the context of pathology criteria in assessing the bioelectric activity of the brain Belorusian State Medical University

\section{Вступление}

Агрессивное поведение зависимых от алкоголя лиц представляет собой общественно значимую проблему, имеющую отчетливую тенденцию к актуализации по мере экономической и социальной нестабильности. Впрочем, данная тема обсуждается и активно исследуется в развитых государствах, что говорит о том, что тематика связанного с потреблением алкоголя агрессивного поведения лишь отчасти определяется социальными факторами и социально-экономическим положением общества [1]. Статистика неуклонно фиксирует рост насильственных преступлений среди зависимых от алкоголя, при этом появляются многочисленные данные об их качественном изменении в направлении возрастания жестокости $[2,3]$.

Механизмы развития агрессивных тенденций поведения в результате потребления алкоголя изучены недостаточно, что сказывается на пока не вполне эффективном результате коррекции и профилактики социальных последствий потребления алкоголя [4]. В частности, не совсем ясно, зависит ли агрессивность поведения от биоэлектрической активности головного мозга.

В наших прежних исследованиях получила подтверждение гипотеза детерминации агрессивного поведения зависимых от алкоголя лиц нейропсихологическими и личностными факторами, а также была обнаружена отчетливая связь такого поведения с особенностями семейного функционирования и профессией. В настоящем исследовании была поставлена задача выявить зависимость агрессивного поведения от биоэлектрической активности головного мозга пациентов.

Целью настоящей работы явилось выявление электрофизиологических критериев агрессивного поведения зависимых от алкоголя лиц.

\section{Материалы и методы}

Всего было исследовано 134 пациента мужского пола с синдромом зависимости от алкоголя в Республиканском научно-практическом центре психического здоровья и Городском клиническом наркологическом диспансере, подписавших информированное согласие на участие в исследовании. В основную группу методом направленного отбора были включены 57 пациентов мужского пола с документально подтвержденными эпизодами гетероагрессивного поведения в состоянии алкогольного опьянения и имевших в связи с этим судимость. Из них 33 человека многократную судимость (подгруппа А) и 24 человека имели однократную судимость (подгруппа Б). Группа сравнения (В) состояла из 77 пациентов мужского пола с синдромом зависимости от алкоголя без подтвержденных эпизодов агрессивного поведения в анамнезе. Пациенты были сопоставимы по возрасту: возраст пациентов подгруппы А основной группы составил $34,2 \pm 6,7$ лет, подгруппы Б основной группы $36,0 \pm 5,2$ и группы

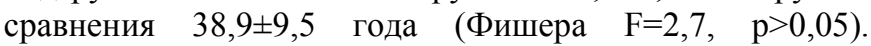
Критериями исключения из исследования явилось агрессивное поведение в состоянии отмены алкоголя, алкогольного психоза и аутоагрессивное поведение, коморбидность с другими психическими расстройствами и отсутствие согласия на участие в исследовании. В исследование не включались зависимые от алкоголя лица, совершившие агрессивные поступки в трезвом состоянии. На момент проведения исследования испытуемые понимали содержание и суть выполняемых ими заданий. Используя судимость в качестве группирующей переменной, из групп сравнения были исключены лица с судимостью без мотива насилия (напр., совершившие экономические преступления).

ЭЭГ-исследование проводилось с использованием безбумажного электроэнцефалографа «Нейрокартограф» 
(МБН, Россия). Многоканальную запись ЭЭГ осуществляли при стандартных условиях: частотная полоса записываемых потенциалов мозга - 0,5-40 Гц, постоянная времени - 0,3 с. Регистрация ЭЭГ проводилась при закрытых глазах в состоянии пассивного бодрствования. Электроды располагались по международной системе $10 * 20$. Исследование включало запись ЭЭГ покоя и регистрацию ответов на стандартные функциональные нагрузки (реакция на открывание и закрывание глаз и 3-х минутная гипервентиляция).

Использовались следующие критерии паталогии при оценке альфа-ритма: 1) постоянное наличие альфаритма (индекс более 50\%) в лобных отделах мозга при биполярной регистрации с электродов, наложенных по сагиттальным линиям с малыми межэлектродными расстояниями; 2) амплитудная межполушарная асимметрия более $30 \%$; 3) частотная асимметрия более 1 колеб./с [5].

Критерии патологии бета-ритма: 1) доминирование низкочастотного бета-ритма по всей конвекситальной поверхности мозга; 2) пароксизмальные разряды бетаритма; 3) очаговая локализация бета-ритма, особенно с повышением его амплитуды; 4) грубая межполушарная асимметрия по амплитуде (более 50\%); 5) приобретение бета-ритмом альфа-подобного ритмичного синусоидального образа; 6) увеличение амплитуды бета-ритма свыше 7 мкВ. Критериями патологии на ЭЭГ считалось появление медленных ритмов: тета и дельта.

Регистрация Р300 осуществлялась по стандартной методике исследования в ситуации случайно возникающего события («oddball» paradigm). Применялась слуховая стимуляция с наличием отдельных триггеров для запуска и усреднения редких (значимых) стимулов тоновых щелчков с частотой наполнения 2000 Гц и частых (незначимых) стимулов - щелчков с частотой наполнения 1000 Гц. Стимулы длительностью 50 мс и интенсивностью 80 дБ подавались бинаурально подавались с частотой 1 Гц в псевдослучайной последовательности с вероятностью появления 30\% для значимых и 70\% для незначимых стимулов. Испытуемому предлагалось реагировать нажатием на кнопку пульта в ответ на редкий, значимый, стимул. Для регистрации использовались монополярные отведения Fp1-M1 и Fp2-M2 (от лобных долей правого и левого полушария ипсилатерально относительно сосцевидных отростков височных костей) по международной системе 10-20, с расположением заземляющего электрода в точке Fpz. Для усиления и усреднения ВП Р300 использовался аппаратный комплекс «Нейрон-Спектр-4/ВПМ» («Нейрософт», Россия), программа «Нейро-МВП». Чувствительность усилителя составляла 20 мкВ/дел при записи, 5 мкВ/дел - при усреднении. Полоса частот - 0,5-35,0 Гц, эпоха анализа 700 мс. Переходное сопротивление электродов не превышало 5кОм. Количество усреднений для значимых стимулов составляло 26-29. Для оценки воспроизводимости ВП у каждого испытуемого исследование Р300 проводилось дважды в независимых временных сериях, которые потом суперпозировались. Измеряли латентности пиков N1, P2, N2, P3, амплитуды пиков N2, P3 как межпиковые амплитуды P2-N2, N2-P3 и; интервал N2-P3 как межпиковая латентность N2-P3 для значимых стимулов. Для незначимых стимулов измеряли латентности пиков N1, P2, N2, амплитуды пиков N2 как межпиковые амплитуды P2-N2. А также фиксировались поведенческие параметры когнитивных ВП Р300: среднее время реакции и процент верных нажатий.

Использовали калькулятор

для эпидемиологических исследований WINPEPI program (Abramson 2004, 2011) - Windows Programs for EPIdemiologists) для теста парных сравнений c определением отношения правдоподобия с вычислением коэффициента $\chi^{2}$ и р-достоверности множественных сравнений. Производилась оценка распределения признаков на нормальность с использованием критерия Колмогорова-Смирнова. Для выявления различий между показателями у сравниваемых групп с нормальным распределением использовали критерий t-Стьюдента, в тех случаях, когда распределение не соответствовало критериям нормальности, применялся его непараметрический аналог - критерий Манна-Уитни. Критический уровень значимости (р) при проверке статистических гипотез в исследовании принимали равным 0,05. Для описательной статистики признаков использовали медиану (Ме) и интервал значений от первого (Q1) до третьего (Q3) квартиля.

\section{Результаты исследования и их обсуждение}

При анализе нарушений альфа-ритма в группах пациентов с зависимостью от алкоголя было выявлено, что для лиц, совершивших неоднократно противоправные действия, характерно смещение альфа-волновой активности. Данный показатель отличал подгруппу А от пациентов группы контроля и сравнения. Смещение альфа-ритма с затылочной области на лобные отделы мозга характерно по данным литературы для лиц с клинически значимой психопатологией личностного характера [5].

Таблица 1. Нарушения альфа-ритма в группах пациентов с зависимостью от алкоголя $\left(\chi^{2}, \mathbf{p}\right)$

\begin{tabular}{|c|c|c|c|c|c|c|}
\hline \multirow{2}{*}{ Категории } & \multicolumn{2}{|c|}{ A: $\mathbf{6}$} & \multicolumn{2}{|c|}{ A:B } & \multicolumn{2}{|c|}{ Б:B } \\
\hline & $\chi^{2}$ & $\mathbf{p}$ & $\chi^{2}$ & $\mathbf{p}$ & $\chi^{2}$ & $\mathbf{p}$ \\
\hline Постоянное наличие альфа-ритма в лобных отделах мозга & 14,2 & $<0,05$ & 11,3 & $<0,05$ & 0,6 & $>0,05$ \\
\hline Амплитудная межполушарная асимметрия более $30 \%$ & 0,7 & $>0,05$ & 0,4 & $>0,05$ & 0,3 & $>0,05$ \\
\hline Частотная асимметрия более 1 колеб./с & 0,2 & $>0,05$ & 0,6 & $>0,05$ & 0,2 & $>0,05$ \\
\hline
\end{tabular}


Таблица 2. Нарушения бета-ритма в группах пациентов с зависимостью от алкоголя $\left(\chi^{2}, \mathbf{p}\right)$

\begin{tabular}{|c|c|c|c|c|c|c|}
\hline \multirow{2}{*}{ Категории/Группы сравнения } & \multicolumn{2}{|c|}{ A: $\mathbf{5}$} & \multicolumn{2}{|c|}{ A:B } & \multicolumn{2}{|c|}{ Б:B } \\
\hline & $\chi^{2}$ & $\mathbf{p}$ & $\chi^{2}$ & $\mathbf{p}$ & $\chi^{2}$ & $\mathbf{p}$ \\
\hline $\begin{array}{l}\text { Доминирование низкочастотного ритма } \\
\text { по конвекситальной поверхности мозга }\end{array}$ & 0,4 & $>0,05$ & 0,6 & $>0,05$ & 0,7 & $>0,05$ \\
\hline Пароксизмальные разряды & 0,9 & $>0,05$ & 0,5 & $>0,05$ & 0,994 & $>0,05$ \\
\hline Очаговая локализация с повышением амплитуды & 0,8 & $>0,05$ & 0,4 & $>0,05$ & 1,2 & $>0,05$ \\
\hline $\begin{array}{l}\text { Межполушарная асимметрия по амплитуде } \\
\text { (более } 50 \% \text { ) }\end{array}$ & 0,7 & $>0,05$ & 0,4 & $>0,05$ & 1,5 & $>0,05$ \\
\hline $\begin{array}{l}\text { Приобретение бета-ритмом альфа-подобного } \\
\text { ритмичного синусоидального образа }\end{array}$ & 0,7 & $>0,05$ & 0,3 & $>0,05$ & 2,1 & $>0,05$ \\
\hline Увеличение амплитуды свыше 7 мкВ & 0,4 & $>0,05$ & 0,2 & $>0,05$ & 0,5 & $>0,05$ \\
\hline
\end{tabular}

Не было выявлено отличий в группах сравнения по бета-волновой активности.

При исследовании слуховых когнитивных ВП Р300в подгруппе А (таблица 3) у по сравнению с подгруппой Б были зарегистрированы статистически значимо более длительный латентный период пиков Р2 $(\mathrm{p}=0,016), \mathrm{N} 2(\mathrm{p}=0,001)$ и $\mathrm{P} 3(\mathrm{p}<0,001)$ в ответ на значимый стимул и более длительный латентный период пиков $\mathrm{N} 1(\mathrm{p}=0,034), \mathrm{P} 2(\mathrm{p}=0,009)$ в ответ на незначимый стимул.

Анализ результатов межпиковой латентности (интервала) N2-P3 слуховых когнитивных ВП Р300 у испытуемых подгруппы А и группы В показал, что у зависимых от алкоголя с несколькими судимостями был зафиксирован статистически значимо более длинный интервал N2-P3 в ответ на значимый $(\mathrm{p}=0,003)$, стимул, в подгруппе Б также был зафиксирован статистически значимо более длинный интервал N2-P3 в ответ на значимый $(p=0,002)$ стимул.

Исследование амплитуд (таблица 4) выявило, что в подгруппе А по сравнению с контрольной группой статистически значимо больше амплитуда пика N2 в ответ на значимый стимул $(\mathrm{p}=0,012)$ и незначимый стимул $(\mathrm{p}=0,048)$. По величине амплитуды Р3 между экспериментальной группой и группой контроля статистически значимых различий обнаружено не было.

Таблица 3. Латентности пиков N1, P2, N2, P3 и интервал N2-P3 слуховых когнитивных вызванных потенциалов Р300 в группах сравнения на значимый и незначимый стимулы, Ме (Q1-Q3), мс

\begin{tabular}{|c|c|c|c|c|c|c|}
\hline $\begin{array}{c}\text { Латентность, } \\
\text { интервал }\end{array}$ & Подгруппа А & Подгруппа Б & Группа В & pA:Б & pA:B & рБ:B \\
\hline $\mathrm{N} 1$ & $\begin{array}{c}125,0 \\
(86,9-159,0)\end{array}$ & $\begin{array}{c}114,5 \\
(92,5-131,2)\end{array}$ & $\begin{array}{c}110,0 \\
(97,0-124,0)\end{array}$ & $>0,05$ & $>0,05$ & $>0,05$ \\
\hline P2 & $\begin{array}{c}206,0 \\
(176,0-233,5)\end{array}$ & $\begin{array}{c}163,5 \\
(145,5-185,2)\end{array}$ & $\begin{array}{c}178,0 \\
(154,7-220,5)\end{array}$ & $<0,05$ & $<0,05$ & $>0,05$ \\
\hline $\mathrm{N} 1 *$ & $\begin{array}{c}124,0 \\
(91,4-153,5)\end{array}$ & $\begin{array}{c}112,0 \\
(99,9-130,7)\end{array}$ & $\begin{array}{c}114,0 \\
(85,5-135,2)\end{array}$ & $<0,05$ & $<0,05$ & $>0,05$ \\
\hline $\mathrm{P} 2 *$ & $\begin{array}{c}214,0 \\
(171,0-230,0)\end{array}$ & $\begin{array}{c}159 \\
(144,7-201,2)\end{array}$ & $\begin{array}{c}165,0 \\
(145,0-196,0)\end{array}$ & $<0,05$ & $<0,05$ & $>0,05$ \\
\hline $\mathrm{N} 2 *$ & $\begin{array}{c}309,0 \\
(242,0-342,0)\end{array}$ & $\begin{array}{c}233,5 \\
(213,7-298,5)\end{array}$ & $\begin{array}{c}262,5 \\
(220,7-301,5)\end{array}$ & $<0,05$ & $<0,05$ & $>0,05$ \\
\hline $\mathrm{P} 3 *$ & $\begin{array}{c}389,0 \\
(367,0-409,5)\end{array}$ & $\begin{array}{c}364,5 \\
(342,5-393,2)\end{array}$ & $\begin{array}{c}326,0 \\
(313,2-347,0)\end{array}$ & $<0,05$ & $<0,05$ & $>0,05$ \\
\hline N2-P3* & $\begin{array}{c}105,0 \\
(75,0-143,0)\end{array}$ & $\begin{array}{c}118,5 \\
(79,7-139,5)\end{array}$ & $\begin{array}{c}90,2 \\
(64,6-122,5)\end{array}$ & $<0,05$ & $<0,05$ & $>0,05$ \\
\hline
\end{tabular}

Таблица 4. Амплитуды пиков Р2, N2 и Р3 слуховых когнитивных вызванных потенциалов Р300 на значимый и незначимый стимулы, Мe (Q1-Q3), мкB

\begin{tabular}{|c|c|c|c|c|c|c|}
\hline Амплитуда & Подгруппа А & Подгруппа Б & Группа В & $\mathbf{p A : Б}$ & $\mathbf{p A : B ~}$ & рБ:В \\
\hline N2 (P2-N2)* & $16,3(8,4-18,1)$ & $12,55(7,27-16,03)$ & $11,5(5,1-15,7)$ & $<0,05$ & $<0,05$ & $>0,05$ \\
\hline P3 (N2-P3)* & $6,2(2,35-11,7)$ & $14,05(6,65-19,55)$ & $12,0(4,8-18,25)$ & $>0,05$ & $>0,05$ & $>0,05$ \\
\hline
\end{tabular}


Выполняя инструкцию по методике ВП Р300 (реагировать нажатием кнопки на значимый стимул), пациенты подгруппы А совершают статистически значимо большее количество ошибок $(\mathrm{p}=0,05)$ по сравнению с пациентами контрольной группы (таблица 5), в то время как значимых различий у пациентов подгруппы Б по данному параметру выявлено не было. Статистически значимых различий между группами по среднему времени реакции также не выявлено.

\section{Таблица 5. Среднее время реакции и процент верных нажатий вызванных потенциалов Р300} в группах сравнения, Мe (Q1-Q3)

\begin{tabular}{|c|c|c|c|c|c|c|}
\hline Параметр & Подгруппа А & Подгруппа Б & Группа В & рА:Б & рA:B & рБ:В \\
\hline Среднее время реакции, мс & 318,0 & 318,0 & 346,0 & $>0,05$ & $>0,05$ & $>0,05$ \\
\cline { 2 - 6 } & $(277,5-371,5)$ & $(277,5-371,5)$ & $(297,0-380,5)$ & & & \\
\hline Процент верных нажатий & 41,7 & 57,7 & 61,9 & $>0,05$ & $>0,05$ & $>0,05$ \\
& $(28,4-55,5)$ & $(43,2-71,0)$ & $(50,0-72,4)$ & & & \\
\hline
\end{tabular}

В дальнейшем планируется изучение нейропсихологических, социальных, психологических аспектов, влияющих на агрессивное поведение у лиц, страдающих алкогольной зависимостью.

\section{Выводы}

1. По данным ЭЭГ у лиц с гетероагрессивным поведением, имевших многократную (подгруппа А) или однократную судимость (подгруппа Б), прослеживалась статистически достоверная разница межполушарной амплитудной асимметрии.

2. Пациенты, имевшие судимость в связи с гетероагрессивным поведением, по данным КВП имели статистически достоверный меньший объем кратковременной и оперативной памяти по сравнению с группой контроля.
3. Пациентам, имевшим судимость в связи с гетероагрессивным поведением, требовалось больше времени для обработки и оценки информации, принятия решения об отнесении слышимого стимула к разряду значимых.

4. У пациентов, имевших многократную судимость в связи с гетероагрессивным поведением (подгруппа A), достоверно удлинен пик N1, входящий в сенсорную составляющую КПВ, что само по себе может рассматриваться как проявление алкогольной сенсорной полиневропатии.

5. Пациенты с многократной судимостью при подсчете значимых стимулов совершали большее количество ошибок, что свидетельствует о снижении уровня направленного внимания.

\section{Литература}

1. Alcohol and interpersonal violence policy briefing. Copenhagen, WHO Regional Office for Europe, 2005 (http://www.euro.who.int/_data/assets/pdf_file/0004/98806/E87347.pdf, accessed 27 September 2012).

2. Дроздов Ю.А. Агрессивное поведение современной молодёжи в контексте социальной ситуации / Ю.А. Дроздов // Социологические исследования. - М., 2003. - № 4. - С. 31-34.

3. Евлашкина Н.М. Психологические факторы и формы проявления агрессии у подростков с девиантным поведением: Автореферат дис. кандидата психологических наук. - Москва, 2012. - 27 с.

4. Игонин А.Л. Нарушения социального поведения больных алкоголизмом (характер проявлений, механизмы формирования, возможность коррекции) / А.Л. Игонин с соавт. // Российский психиатрический журнал - 2009. - № 1. C. $77-82$.

5. Гнездицкий В.В. ЭЭГ и клиническая электроэнцефалография / В.В. Гнездицкий. - М: Медпресс, 2004. - 648 с.

\section{References}

1. Alcohol and interpersonal violence policy briefing. Copenhagen, WHO Regional Office for Europe, 2005 (http://www.euro.who.int/_data/assets/pdf_file/0004/98806/E87347.pdf, accessed 27 September 2012).

2. Drozdov Yu.A. Agressivnoye povedeniye sovremennoy molodozhi v kontekste sotsial'noy situatsii / Yu.A. Drozdov // Sotsiologicheskiye issledovaniya. - M., 2003. - № 4. - S. 31-34.

3. Yevlashkina N.M. Psikhologicheskiye faktory $\mathrm{i}$ formy proyavleniya agressii u podrostkov s deviantnym povedeniyem: Avtoreferat dis. kandidata psikhologicheskikh nauk. - Moskva, 2012. - 27 s.

4. Igonin A.L. Narusheniya sotsial'nogo povedeniya bol'nykh alkogolizmom (kharakter proyavleniy, mekhanizmy formirovaniya, vozmozhnost' korrektsii) / A.L. Igonin s soavt. // Rossiyskiy psikhiatricheskiy zhurnal - 2009. - № 1. - S. 77-82.

5. Gnezditskiy V.V. EEG i klinicheskaya elektroentsefalografiya / V.V. Gnezditskiy. - M: Medpress, $2004 .-648$ c.

Дата надходження рукопису до редакції: 09.06.2020 p. 
Целью настоящей работы явилось выявление электрофизиологических критериев агрессивного поведения зависимых от алкоголя лиц.

Материалы и методы. Всего было исследовано 134 пациента мужского пола с синдромом зависимости от алкоголя с документально подтвержденными эпизодами гетероагрессивного поведения в состоянии алкогольного опьянения и имевших в связи с этим судимость. Пациентам проводилось ЭЭГ-исследование, оно включало запись ЭЭГ покоя и регистрацию ответов на стандартные функциональные нагрузки.

Результаты. Пациентам, имевшим судимость в связи с гетероагрессивным поведением, требовалось больше времени для обработки и оценки информации, принятия решения об отнесении слышимого стимула к разряду значимых.

Выводы. По данным ЭЭГ у лиц с гетероагрессивным поведением, имевших многократную (подгруппа А) или однократную судимость (подгруппа Б), прослеживалась статистически достоверная разница межполушарной амплитудной асимметрии.

Пациенты, имевшие судимость в связи с гетероагрессивным поведением, по данным КВП имели статистически достоверный меньший объем кратковременной и оперативной памяти по сравнению с группой контроля.

Ключевые слова: зависимость от алкоголя, биоэлектрическая активность, агрессивное поведение.

Метою цієї роботи є виявлення електрофізіологічних критеріїв агресивної поведінки залежних від алкоголю осіб.

Матеріали та методи. Всього було досліджено 134 пацієнта чоловічої статі з синдромом залежності від алкоголю 3 документально підтвердженими епізодами гетероагрессівного поведінки в стані алкогольного сп'яніння і мали в зв'язку з цим судимість. Пацієнтам проводилося ЕЕГ-дослідження, воно включало запис ЕЕГ спокою і реєстрацію відповідей на стандартні функціональні навантаження.

Результати. Пацієнтам, які мали судимість у зв’язку з гетероагрессівним поведінкою, потрібно більше часу для обробки і оцінки інформації, прийняття рішення про віднесення чутного стимулу до розряду значущих.

Висновки. За даними ЕЕГ у осіб з гетероагрессівним поведінкою, що мали багатократну (підгрупа А) або одноразову судимість (підгрупа Б), простежувалася статистично достовірна різниця міжпівкульової амплітудної асиметрії.

Пацієнти, які мали судимість у зв'язку з гетероагрессівним поведінкою, за даними КВП мали статистично достовірний менший обсяг короткочасної і оперативної пам'яті в порівнянні з групою контролю.

Ключові слова: залежність від алкоголю, біоелектрична активність, агресивна поведінка.

The aim of this work was to identify electrophysiological criteria for aggressive behavior in alcohol-dependent individuals.

Materials and methods. A total of 134 male patients with alcohol dependence syndrome with documented episodes of heteroaggressive behavior in a state of alcoholic intoxication and with a criminal record were investigated. The patients underwent an EEG study, which included recording an EEG at rest and recording responses to standard functional loads.

Results. Patients who had a criminal record in connection with heteroaggressive behavior required more time to process and evaluate information, and to make a decision about classifying the audible stimulus as significant.

Conclusions. According to EEG data, patients with heteroaggressive behavior who had multiple (subgroup A) or single convictions (subgroup B) showed a statistically significant difference in hemispheric amplitude asymmetry.

Patients who had a criminal record due to heteroaggressive behavior, according to KVP data, had a statistically significant lower volume of short-term and working memory compared to the control group.

Key words: alcohol dependence, bioelectric activity, aggressive behavior.

Конфлікт інтересів: відсутній.

Conflicts of interest: authors have no conflicts of interest to declare.

\section{Відомості про авторів}

Сайков Антон Дмитриевич - врач-психиатр-нарколог, УЗ «Городской клинический наркологический диспансер»; 220035, Республика Беларусь, г. Минск, ул. Гастелло, 16.

+375 (29) 188-26-08, antonsaikov@ mail.ru.

Скугаревский Олег Алексеевич - доктор медицинских наук, профессор, ГУ «Республиканский научно-практический центр психического здоровья», кафедра психиатрии и медицинской психологии БГМУ; 220053, Республика Беларусь, г. Минск, Долгиновский тракт, 152.

skugarevsky@gmail.com.

Минзер Марина Фёдоровна - заведующая отделением функциональной диагностики ГУ «Республиканский научнопрактический центр психического здоровья»; 220053, Республика Беларусь, г. Минск, Долгиновский тракт, 152. +375 (17) 286-87-34, neirof@mail.ru. 